\title{
Professores de Matemática em atividade de ensino de álgebra: Apropriações da teoria histórico-cultural
}

\author{
Núbia Cristina dos Santos Lemes ${ }^{i}$ \\ Universidade Estadual de Goiás, Brasil \\ Wellington Lima Cedroii \\ Universidade Federal de Goiás, Brasil
}

\begin{abstract}
Resumo
Este artigo tem o objetivo de apresentar as evidências das apropriações de um grupo de professores de Matemática que, inconformados com a situação do ensino da álgebra, participaram de um curso de formação que os colocou em atividade de ensino. Neste curso, os professores tiveram contato com a teoria histórico-cultural e com as atividades orientadoras de ensino. Trata-se de uma pesquisa qualitativa que se utilizou de um experimento didático desenvolvido com um grupo de professores de Matemática da Educação Básica. Os principais resultados desta pesquisa indicam a importância de ações de formação que permitam que os professores possam inserir-se em um movimento de produção de sentidos ao aprenderem e ensinarem álgebra numa proposta que entende o conhecimento matemático como um produto histórico-cultural.
\end{abstract}

Palavras-chave

Formação de professores; Ensino de álgebra; Teoria histórico-cultural

\section{Introdução}

Este artigo é fruto da dissertação de mestrado de Lemes (2012). A dissertação teve como objetivo principal evidenciar a produção de sentidos por parte de professores de Matemática, em atividade de ensino, com relação aos princípios da proposta didática lógico-histórica da álgebra (Sousa, 2004). 
O par lógico-histórico é reflexo da teoria histórico-cultural (Vigotski, 2008), quando compreende o conceito como produto humano e transcende $\mathrm{O}$ passado, o presente, e permanece para além do seu tempo. A problematização desse estudo se fez em torno do seguinte questionamento: quais as evidências da produção de sentidos dos princípios da proposta didática lógico-histórica da álgebra por professores de Matemática em atividade de ensino?

No presente artigo, enfatizamos os resultados obtidos com a realização de um curso de formação continuada para professores de Matemática, desenvolvido com o intuito de apresentá-los a uma proposta teórica de organização do ensino fundamentada na perspectiva das atividades orientadoras de ensino (Moura, 2010). Assim, apresentamos alguns recortes desse estudo que evidenciaram as ações de formação que levaram o professor à produção de sentidos sobre a organização do ensino da álgebra.

Esta pesquisa tem um cunho qualitativo e foi desenvolvida metodologicamente tendo como base o experimento didático (Cedro \& Moura, 2010). O curso de formação (a organização do mesmo está apresentada no anexo), que foi a objetivação do experimento didático, teve duração de cinco meses, perfazendo um total de trinta horas distribuídas em sete encontros, filmados com o consentimento dos participantes. A dinâmica organizacional do curso estruturou-se em torno da vivência de situações que permitissem ao professor compreender o significado da "atividade de ensino" (Moura, 2010). Nesta perspectiva, durante o curso, os docentes puderam, inicialmente, apresentar as tarefas de ensino de álgebra que consideravam mais adequadas ao processo de aprendizagem do conhecimento algébrico; elaborar atividades de ensino compartilhando-as com o grupo; apresentar a incorporação de sugestões do coletivo; e desenvolver atividades em suas respectivas salas de aula, com o acompanhamento da pesquisadora.

Neste artigo, inicialmente abordaremos a educação e a escola a partir dos fundamentos da teoria histórico-cultural. Trataremos das atividades de ensino, posteriormente apresentaremos o conceito de Atividade Orientadora de Ensino (AOE) proposta por Moura (2010). Por fim, discutiremos e analisaremos as evidências da produção de sentidos dos princípios da proposta didática lógico-histórica pelos professores participantes do curso de formação. 


\section{Uma compreensão do histórico-cultural para a educação e a escola}

Preparar o educando para a vida, para o seu pleno desenvolvimento, compreende ações amplas que não se encerram na transmissão de conteúdos; exige que o professor organize o ensino de um modo que o aluno possa perceber a necessidade de se apropriar do conhecimento como ferramenta para o seu desenvolvimento como pessoa, tornando-se capaz de fazer escolhas conscientes.

Nesse sentido, remetemo-nos ao professor de Matemática, o qual lida com um saber responsável pela compreensão da grande maioria dos movimentos que nos cercam - no desconto por uma mercadoria comprada à vista, lidamos com porcentagem; na quantidade entre a dosagem de medicamento e a massa do sujeito, tem-se a proporção; na previsão de que poderá faltar água à humanidade num tempo não muito distante, tem-se a projeção estatística -, mas, apesar disto, se vê diante de uma parcela extremamente significativa de indivíduos que rejeitam esse conhecimento. Assim, podemos nos perguntar: como o professor de Matemática pode organizar o ensino de modo a alterar pré-juízos sobre esta ciência, tornandoa compreensível?

Esta mudança inicia-se pela adoção de estratégias baseadas na busca pelo sentido ao que é ensinado. Somente assim, de fato, poderá acontecer a apropriação dos conhecimentos que favoreçam a alfabetização científica e o desenvolvimento do indivíduo. A alfabetização científica é entendida como a capacidade do indivíduo em compreender e produzir o conhecimento científico, questionar o óbvio e fugir do encapsulamento do ensino que, segundo Moyses (2006):

Trata-se do extremo isolamento que cresce a cada dia na escola em relação ao mundo que a rodeia. É como se o processo de escolarização encorajasse a ideia de que no 'jogo da escola' o que conta é aprender vários tipos de regras simbólicas, aprendizagem essa que deve ser demonstrada no seu próprio interior (p. 59).

No isolamento escolar comumente são exercitados procedimentos que envolvem a mera repetição de regras e algoritmos para se chegar a resultados satisfatórios que, na maioria das vezes, exigem uma única resposta correta. Embora a aprendizagem sistematizada do algoritmo seja de extremo valor, esse processo carece de sentido, como afirma Moyses (2006): 
Se o professor e alunos defrontam-se com sentenças, regras e símbolos matemáticos sem que nenhum deles consiga dar sentido e significado a tal simbologia, então a escola continua a negar ao aluno [...] uma das formas essenciais de ler, interpretar e explicar o mundo (p. 67).

$\mathrm{Na}$ perspectiva defendida por Moyses (2006) fica evidente que o significado da escola tem sido ignorado. O pior é que esta situação vai se constituindo em um círculo no qual movimentos tangenciais são raros. 0 professor vai ensinando da maneira como lhe ensinaram. Talvez isso justifique a constatação de que os alunos não gostam das aulas e dos professores, não encontram prazer na escola, vão apenas para "passar de ano", escutam o professor mas não prestam atenção ao que ele diz e culpam-no de seus fracassos.

O ensino que provoca o desenvolvimento de práticas comuns às que anunciamos deve ser evitado. Urge considerar as relações sociais num contexto que envolve a negociação de sentidos, onde haja espaço para refutações, investigação, criatividade, ação, vivência e quebra de tabus que insistem em promulgar a Matemática como estacionária, fixa, imutável ou que se resume em técnicas e procedimentos infalíveis.

Neste cenário encontramos um caminho favorável que nos oferece pistas de como lidar com o terreno fértil da Matemática, como compreendê-la e ensiná-la: é a teoria histórico-cultural, base teórica dos trabalhos de Sousa (2004), Cedro (2008), Moretti (2007) e Lopes (2009), nos quais buscamos referenciais que enfocam o papel do professor em organizar o ensino de modo intencional e planejado.

A teoria histórico-cultural é um campo fecundo de descobertas. $\mathrm{Na}$ Matemática, ela dirige a compreensão histórica dos conceitos como fruto da criação humana (Moura, 2000); leva também à investigação da força que tem a ciência Matemática, permite vivenciar caminhos trilhados por nossos precursores que legitimaram conhecimentos dados hoje como prontos e inquestionáveis, abre a possibilidade de compreender os porquês de certos caminhos serem descartados e outros não. A teoria histórico-cultural, conforme Moura (2000), constitui saída na compreensão das relações entre o psiquismo e as manifestações sociais e culturais, a história da humanidade como corrente psicológica que estuda o desenvolvimento psíquico humano e sua relação com a educação, enfoca o social, o cultural e o histórico, além de 
outros fatores determinantes na compreensão da mente humana e de seu desenvolvimento.

Entendemos que o conhecimento matemático está em movimento e seu estudo exige a vivência de situações que apresentem esse movimento ao longo da história da humanidade. Assim, é imperativo que nos cursos oferecidos aos professores ocorra a inserção de atividades que levem em consideração o desenvolvimento histórico do conhecimento, as situações que reconheçam a aprendizagem da Matemática como necessidade do ser humano e a possibilidade de conhecer e intervir no mundo. Por essas premissas, atentamos para o papel de um ensino voltado a práticas em que os envolvidos interajam, compartilhem, contemplando-se a cultura e a história na constituição dos saberes, os quais advêm de um contexto histórico-cultural onde o homem é considerado produto e produtor da sociedade por transformar a natureza e ser transformado por ela, no entendimento de natureza como realidade humana.

Pondera Duarte (2008) que, ao produzir meios para sobreviver, o que implica construir habitações, cultivar alimentos, produzir vestuário, satisfazer suas necessidades e criar novas, o homem compõe seu primeiro ato histórico. O trabalho, por possibilitar o desenvolvimento humano, é uma atividade humana por excelência; assim o consideram Rigon, Asbahr e Moretti (2010, p. 18), acrescentando que essa exclusividade se dá pela atividade da consciência e por ela "o homem constitui-se efetivamente humano", no sentido de compreender o mundo individual e social e poder controlar a natureza.

Ter à disposição a natureza e a possibilidade de modificá-la para satisfazer-se são garantias para a existência do homem. Contudo, ele aspira por conforto, bens materiais e conquistas intelectuais; está sempre em busca de satisfazer seus desejos e gerar outros. Logo, temos uma conduta caracterizada pela dialética entre a objetivação e a apropriação, numa lógica que sintetiza "a dinâmica essencial do trabalho e, por decorrência, a dinâmica essencial do processo de produção e reprodução da cultura humana" (Duarte, 2008, p. 24). Vale ressaltar que é na relação entre o homem e a natureza que surge o processo chamado de apropriação e, quando o homem modifica a natureza imprimindo-Ihe suas características, dá-se a objetivação. Podemos dizer então que a apropriação desencadeia a objetivação e vice-versa, pois no decurso da sua atuação sobre a natureza o homem nela interfere e imprimeIhe novas feições. 
O processo de apropriação é sempre mediatizado pelas relações entre os seres humanos, por isto a coletividade é tão importante na formação dos indivíduos. Um espaço de formação que intente apropriações e objetivações pelos envolvidos deve oferecer a oportunidade do compartilhamento de ações e da negociação de decisões e sentidos. Justifica-se então o papel fundamental das instituições de formação, sejam escolas ou universidades. Nesses locais, em se considerando que o trabalho educativo é intencional e dirigido por fins, desenvolvem-se nos indivíduos a consciência, o pensamento, a humanização.

\section{A escola como espaço de aprendizagem: a atividade de ensino em destaque}

O ser humano tem com a realidade externa uma relação mediatizada porque, ao transformar a natureza, é também transformado por ela. Nesta atuação, uma característica 0 distingue dos outros animais: a intencionalidade. Assim, sua atividade se estrutura pela necessidade, por motivos e finalidades que, ao mesmo tempo, se interrelacionam e se transformam.

Moura (1996) afirma que, ao ensinar, o professor tem que "resolver o problema do ensino", cuja solução se pauta em descobrir os dados do ensino que envolvem a organização do conteúdo para atingir objetivos. Quanto mais informado sobre o aluno - ou seja, sobre o processo como ele aprende, como ele se relaciona e como ele se integra socialmente, enfim, sobre as características que influenciam a forma de aprendizagem -, mais facilidade $o$ professor terá em selecionar conteúdos para atingir seu objetivo. Nesse fazer, o docente buscará resolver o problema do ensino, que é uma ação que se pauta pela atividade de ensino que tem o conhecimento teórico como objetivo principal, conforme indicam Rosa, Moraes e Cedro (2010).

Moura (1996,) assevera que "a escola como um lugar onde se aprende, tem como corolário a escola em que se ensina" (p. 29). Leva-nos a concluir que, para a escola ser um lugar de aprendizagem, o professor deve estar em atividade de ensino, organizando situações que permitam o compartilhamento, a troca, a negociação, "[...] onde as pessoas cooperem, discutam e colaborem. É bem diferente de organizar uma situação onde só um trabalha e resolve a situação para todos" (Cedro, 2008, p. 154). 
A atividade do professor necessita relacionar objetivos e instrumentos, o que exige uma organização de conteúdos que dê conta dos novos objetivos; isso envolve constante estudo na busca de respostas para os problemas do ensino, cujos planos de solução encontram-se no nível de desenvolvimento do professor e do aluno. De acordo com Moura (1996),

A atividade de ensino, assumida como núcleo da ação educativa, nos parece ter duas dimensões: a de formação do professor e a de formação do aluno. Ambas têm elementos comuns: a situação-problema, uma dinâmica de solução e uma possibilidade de avaliação. (p. 32).

A atividade de ensino é constituída na articulação entre a teoria e a prática. Essa conexão fundamental é condição da transformação do sujeito. Para tanto, o professor não pode esquecer que os conteúdos existentes nos livros didáticos são para resolver um problema dele, não foram inventados somente para preencher páginas das obras, eles estão ali porque são fruto de uma construção histórica, de uma construção humana. Sendo então arquitetados pelo homem, devem existir para servi-lo; para tanto, ao selecioná-los, o professor deve ter em foco o conhecimento como problema a ser resolvido por ele e pelos alunos.

Ao considerar as particularidades da turma, suas diferenças individuais e a definição de um objetivo de formação como um problema coletivo, o professor acaba se inserindo em um movimento duplo, no qual ele ensina mas também aprende. Assim, a atividade de ensino é considerada processual e não um produto, conforme podemos inferir das palavras de Moretti (2007): "O professor, movido pela sua necessidade, encontra-se em atividade de ensino antes, durante e depois de seu encontro com os alunos na sala de aula" (p. 100).

$\mathrm{Na}$ organização do ensino de um modo que permita a interação entre os envolvidos, a negociação de sentidos, o diálogo e a delimitação de conteúdos e instrumentos didáticos, a atividade de ensino passa a nortear a dinâmica da aula; daí ser considerada como atividade orientadora de ensino, como salienta Moura (1996, cit. em Moretti, 2007):

A atividade orientadora de ensino insere-se numa atividade mais geral que é a atividade de ensino cuja necessidade que a motiva é ensinar e para isso é necessário organizar o ensino de modo a favorecer a aprendizagem dos alunos - o que é a necessidade da atividade orientadora de ensino. Assim a atividade orientadora de ensino transforma-se numa das ações da atividade de ensino (pp. 99-100, grifos da autora). 
Ensinar é o motivo da atividade de ensino, mas para isso o professor precisa organizá-lo, e para tanto deve viabilizar o aprendizado dos alunos que permita o desenvolvimento do pensamento teórico.

\section{Atividade Orientadora de Ensino (AOE) como objetivação da atividade de ensino}

A Atividade Orientadora de Ensino (AOE) se caracteriza por sua intencionalidade na busca de resolução de uma situação-problema. Ao mesmo tempo em que forma o aluno, forma também o professor. Desse modo, a AOE é a "realização do conjunto de ações coletivas negociadas e planejadas com o objetivo de educar alguém. O que, em última instância, é tomar a atividade orientadora de ensino como um problema em movimento" (Moura, 1996, p. 42).

A contribuição de uma atividade orientadora de ensino no desenvolvimento da consciência dos sujeitos que a realizam deve estar clara para eles; por isso, a idealização dessa atividade deve ser intencional, pautarse por um objetivo, ter um sentido - daí constituir-se formadora tanto para o aluno quanto para o professor. A atividade orientadora de ensino se dá quando o motivo do que se faz passa a ser o objeto. No caso do professor, o motivo dele ensinar deve coincidir com o seu objeto, o ensino. Da mesma forma, para o aluno, o motivo de estar na escola deve ser adquirir conhecimentos e o seu objeto é o conhecimento: "os conhecimentos teóricos são ao mesmo tempo objeto e necessidade na atividade de aprendizagem" (Moura, 2010, p. 92). Quando o aluno não objetiva adquirir o conhecimento e passa a realizar tarefas sem um propósito, ele está apenas treinando procedimentos - por exemplo, quando estuda um conteúdo apenas para se sair bem em uma prova.

Em nossa visão, professores de Matemática ao acreditarem que as simplificações facilitam a compreensão, apresentam ao aluno o conteúdo como se ele fosse criado da noite para o dia exigindo que o compreendam. As tarefas que os alunos fazem se resumem em compreender como resolver, isto é, encontrar respostas corretas para os problemas que se seguem às explicações do professor. Os alunos adaptam-se aos conceitos, familiarizamse e trabalham com eles, sem, no entanto, compreendê-los. Quanto a isso, Cedro (2008) afirma: 


\begin{abstract}
Nesse contexto, a Matemática caracteriza-se completamente pela mecanicidade e por negar a historicidade, pois o seu conteúdo apresenta-se pronto e acabado, o que exige do indivíduo somente a reprodução e memorização de procedimentos e técnicas, excluindo totalmente a possibilidade de criação (p. 160).
\end{abstract}

Grosso modo, afirmamos que a junção de três momentos da atividade orientadora de ensino - antes, durante e depois - constituem a atividade de ensino. A etapa relacionada ao antes se refere à análise das necessidades que geraram o conceito estudado, ou seja, uma investigação histórica do conteúdo; o durante envolve a organização do ensino (por exemplo, a formação de grupos para favorecer a aprendizagem do conteúdo); e o depois é alusivo à avaliação dos trabalhos desenvolvidos, tanto pelos alunos quanto pelo professor.

A atividade orientadora de ensino para constituir-se como orientadora deve tornar-se formadora para o professor e para o aluno. É formadora para o professor tendo em vista que, ao organizar as atividades para atender os objetivos de seu ensino, estará se formando ao buscar estratégias para atingir tais objetivos a fim de formar o aluno; este, movido pelo desejo de aprender, estará em formação ao desenvolver uma atividade elaborada com intencionalidade pelo professor. Nessa direção, deve haver uma situaçãoproblema que proporcione o empenho do grupo em solucioná-la coletivamente, levando-o a perceber que as ações individuais se refletem no outro; assim acontece na vida em sociedade e, dessa forma, o aluno é preparado para o convívio social.

Tendo como base essas ideias, organizamos um curso de formação para docentes da Educação Básica que ensinavam Matemática em uma rede pública de ensino. Na próxima seção discutiremos como esses professores se apropriaram dos fundamentos teóricos durante a sua participação.

\title{
O curso de formação: o experimento didático
}

O que move o sujeito em determinada fase de sua vida é a sua atividade principal; para uma criança sua atividade principal é o brincar; para um adulto a atividade principal é o trabalho. Leontiev (cit. em Moura, 1996) "chama de atividade principal aquela em cuja forma surgem outros tipos de processos e dentro da qual eles são diferenciadas; a atividade na qual processos psíquicos particulares tomam forma ou são reorganizados" (p. 37). 
Conforme a profissão, há um motivo que a justifique; o motivo do trabalho do professor deveria ser o ensino para gerar aprendizagem e levar ao desenvolvimento do indivíduo, garantindo-lhe apropriar-se dos bens culturais. No entanto, o que vem ocorrendo em relação ao trabalho do professor é que o seu motivo principal tem sido outro: a preparação do aluno para ser aprovado em uma prova, como o vestibular ou o ENEM (Exame Nacional do Ensino Médio).

Considerando-se tal constatação e o que discutimos quanto ao que é necessário ao docente em sua atividade, a formação do professor exige práticas que o capacitem a pensar, gerar conhecimento e elaborar o seu próprio material de trabalho. Por este motivo, no processo de aprendizagem do professor devem se fazer presentes ações mediadas, colaborativas e interativas; no "movimento de aprendizagem, solicita-se não apenas um papel ativo, mas interativo com diferentes conhecimentos na permanente atividade de aprender" (Araújo \& Moura, 2008, p. 79, grifo dos autores).

Concordando com Araújo e Moura (2008), promovemos um espaço em que predominou o trabalho colaborativo, sendo oportunizado aos professores o estudo da teoria histórico-cultural e a inserção de seus pressupostos na elaboração de atividades orientadoras de ensino. Assim, foi organizado um espaço de aprendizagem sob a metodologia de um experimento didático.

Cedro \& Moura (2010) afirmam que o experimento didático se origina das ideias de Vigotski e, embora se fale em experimento, mencionam que este termo não se refere "[...] à parte da pesquisa na qual as variáveis são manipuladas e seus efeitos sobre outras variáveis são observados" (p. 58). Para eles esta é uma proposta formativa que vai além de buscar a relação causa e efeito: permite atuar nos processos psíquicos dos envolvidos; nesse sentido, Davidov (1988, cit. em Cedro \& Moura, 2010) assim aponta:

O experimento didático é um método de investigação psicológica que permite estudar a essência das relações internas entre os diferentes procedimentos da educação e do ensino e o correspondente caráter de desenvolvimento psíquico do sujeito. Um dos pontos essenciais dessa perspectiva é que ela pressupõe a intervenção ativa do pesquisador nos processos psíquicos que ele estuda (p. 59).

O experimento didático foi realizado com cinco professores e professoras (denominados com as seguintes siglas: Ad; Al; L; R; e U). Com relação à formação acadêmica dos professores, apenas um não havia 
concluído o curso de graduação à época da pesquisa e outro não era graduado em Matemática. Eles pertenciam às redes públicas municipal e estadual, sendo dois professores da rede municipal e três da rede estadual. Dois docentes eram pós-graduados, sendo um stricto-sensu e um lato-sensu. Declararam que se realizam profissionalmente quando os alunos aprendem. Eles querem produzir suas próprias propostas de trabalho, sendo que a escolha pela Matemática como profissão ou a sua prática teve influência direta de algum professor. Além disso, querem contribuir com a formação do outro, mostrando a presença da Matemática na vida deles.

O curso de formação desenvolvido com esses professores constituiu um experimento didático em que o nosso intuito foi captar as evidências da produção de sentidos dos princípios da proposta didática lógico-histórica da álgebra quando estavam em atividade de ensino. A organização do curso se deu do seguinte modo: 1) Elaboração de exercícios envolvendo conteúdos sobre álgebra, pelos cursistas, como os trabalhados em suas salas de aula; 2) Compartilhamento dos exercícios com o grupo; 3) Estudo dos fundamentos teóricos da perspectiva lógico-histórica e do ensino da álgebra; 4) Reelaboração das propostas iniciais numa perspectiva lógico-histórica e reapresentação; 5) Aplicação nas salas de aula das propostas reelaboradas; 6) Relatórios sobre o desenvolvimento em suas salas de aula.

A formação permitiu que os professores inicialmente tivessem contato com a teoria, em seguida com atividades orientadoras de ensino que incorporavam a teoria e, após os orientamos a construírem atividades que incorporassem os princípios da abordagem discutida no curso. Esse movimento possibilitou a apropriação dos pressupostos da teoria em questão, a produção de sentidos pessoais, bem como a incorporação dos elementos dessa teoria na elaboração de atividades orientadoras de ensino, gerando com isso uma ação de qualidade nova ao estarem em atividade de ensino.

Rosa et al. (2010) afirmam que "são as necessidades humanas que mobilizam o homem para a produção de instrumentos"; a necessidade de responder como se daria a organização do ensino numa teoria históricocultural motivou os professores a participarem do curso, e desta forma estar em atividade de ensino organizando instrumentos que desencadeassem aprendizagens significativas em seus alunos. 
Sabemos que existem diferenças entre o desenvolvimento cognitivo da criança e do adulto; porém, Araújo \& Moura (2008) consideram que "a aprendizagem do educador, sujeito adulto, tem uma lógica semelhante à do aluno: ambos ocupam, em níveis e contextos diferentes, um mesmo estatuto de aprendizes" (p. 88). Com esta afirmação queremos dizer que é preciso considerar, na formação do professor, o processo histórico-cultural; se o aprendizado e o desenvolvimento perduram por toda a vida, então o professor pode aprender e, consequentemente, se desenvolver enquanto assim se dispuser. Por esse motivo, quando num espaço social em que companheiros mais capazes podem cooperar, o professor pode sim ampliar seu arcabouço teórico, pois tem:

Em relação ao seu saber docente, um nível de desenvolvimento real e um nível de desenvolvimento potencial, e é na zona de desenvolvimento proximal, configurada como um ambiente de interação, que as ações de formação devem incidir (Araújo \& Moura, 2008, p. 90).

Por acreditar no que os autores acima anunciam e que o professor tem capacidade cognitiva de aprender enquanto atua, é que organizamos o espaço de aprendizagem de modo que as ações desenvolvidas fossem mediadoras entre os conhecimentos do curso e os docentes. Além do mais, os grupos que agem de forma colaborativa têm maiores chances de vencer a "racionalidade técnica" que insiste em permear os domínios de nossas escolas; no coletivo se ressignificam saberes, surgem alternativas conjuntas para solucionar angústias muitas vezes comuns ao grupo, - aliás, "[...] ações isoladas dão pouca consistência e visibilidade à atividade do indivíduo, principalmente quando nos referimos à esfera educacional" (Cedro, 2008, pp. 197-198).

A cooperação dos companheiros redimensiona a prática do professor. Se coletivizando os pares aperfeiçoam a capacidade de produzirem conhecimentos característicos da profissão docente, visto que o conhecimento é um produto social, nos fala Nóvoa (1992), e acrescenta:

A troca de experiências e a partilha de saberes consolidam espaços de formação mútua, nos quais cada professor é chamado a desempenhar, simultaneamente, o papel de formador e de formando. O diálogo entre os professores é fundamental para consolidar saberes emergentes da prática profissional. Mas a criação de redes colectivas de trabalho constitui, também, um factor decisivo de socialização profissional e de afirmação de valores próprios da profissão docente. O desenvolvimento de uma nova cultura 
profissional dos professores passa pela produção de saberes e de valores que deêem corpo a um exercício autónomo da profissão docente (Nóvoa, 1992, p. 26).

Para analisar como todos esses elementos teóricos apresentados até ao momento foram apropriados pelos professores, partimos do pressuposto de que tudo está em movimento, em mudança, em transformação, ou seja, em fluência. Assim, para buscar na realidade os indícios reveladores da produção de sentidos dos princípios da proposta didática lógico-histórica da álgebra pelos participantes da pesquisa, compusemos unidades de análise que nos permitiram a compreensão da essência do fenômeno. As unidades de análise criadas foram as seguintes: 1) Um novo sentido para a organização do ensino; e 2) Sentidos do lógico-histórico do conceito nas atividades orientadoras de ensino.

Sob os princípios da teoria histórico-cultural e a partir das unidades de análise determinadas, elencamos episódios que revelam, no processo formativo dos professores, ações de aprendizagem decorrentes do conhecimento adquirido no experimento didático realizado. São eles: i) $A$ criação de motivos para a aprendizagem; ii) O compartilhamento conduzindo a reflexão crítica das ações; iii) O sentido de organização do ensino; e iv) Situação desencadeadora de aprendizagem. Neste artigo não apresentaremos cada um destes episódios, mas faremos uma exposição das evidências decorrentes destes episódios e das unidades de análise.

\section{As evidências da produção de sentidos}

$\mathrm{Na}$ trajetória pessoal dos participantes do experimento didático realizado, foram revelados motivos distintos, pessoais ou não, que influenciaram os professores na escolha da docência e, por consequência, na busca de aprendizagem. Diante do desafio de elaborar as atividades orientadoras de ensino - a proposta de atividade final do curso -, os professores pesquisaram em fontes alternativas além do livro didático para aprofundamento do conteúdo, adotando assim uma organização intencional de ações expressas no conteúdo das atividades a serem apresentadas ao grupo e aplicadas aos alunos em suas salas de aula. Essa situação promoveu o formar-se dos alunos e dos professores. Além disso, nos discursos dos docentes pudemos detectar que se sentiram responsáveis por organizar 0 
ensino. Mostraram-se motivados por propiciar ao aluno aprender e se desenvolver, sendo esta uma criação de motivo para a aprendizagem: "[...] a consciência da ação, que ocorre pela reflexão, faz parte da atividade de aprendizagem, constituindo o elemento que permite ao sujeito o domínio e a mobilidade da atividade" (Lopes, 2009, p. 163), ocasionando um modo particular de organizar o ensino atendendo as necessidades dos alunos.

Conforme mencionamos, uma das etapas do curso de formação envolveu a elaboração de atividades orientadoras de ensino, o que serviu para mobilizar os professores para o resgate do planejamento com foco em organizar o ensino, ou seja, o exercício da autoria e autonomia e, quando sentiam dificuldades na elaboração, se subsidiavam nas atividades que apresentamos durante o curso, sendo que algumas de suas atividades até se assemelharam a elas.

Planejar as atividades orientadoras de ensino desafiou os professores a buscarem estratégias como a seleção de fontes de pesquisa para resolver o problema da necessidade de realizar um planejamento destinado à concretização de um objetivo determinado. Seus conhecimentos iniciais foram mobilizados na escolha de instrumentos adequados para um público-alvo - a sala de aula de cada um deles. Ações dessa natureza, segundo Moura (2000), "são seguramente, fontes de conteúdo de formação do professor que necessita assumir de forma consciente um dos seus objetivos: a organização do ensino" (p. 105). Sendo o ensino planejado e replanejado quando necessário, há maiores chances de garantir a formação de conhecimentos pelos alunos. O discurso de um dos participantes, a seguir, confirma isso:

Eu acredito que [...] o planejamento é muito dinâmico. Porque tem professor assim, planejou a aula e chega lá na sala de aula, às vezes um aluno faz uma pergunta, outro aluno questiona aquilo de uma forma diferente, e aí às vezes o professor fala: não, mas não está no planejamento, eu não planejei desta forma; então nós temos que fazer é assim, e se você às vezes utiliza esta metodologia com o aluno então você não vai conseguir atingir seu objetivo. É lógico que você tem que ir para a sala de aula com o planejamento, agora o planejamento é a espinha dorsal da aula, mas ali você pode, dependendo da situação e do interesse e entusiasmo que os alunos tiverem tendo em relação à aula, aquilo pode ganhar vertente, e para surtir efeito você tem que acompanhar os alunos, direcionando para não deixar a coisa sair fora. (Discurso de professor participante da formação). 
No discurso do professor participante da formação fica claro que ele reconhece a funcionalidade do planejamento como organizador de ações e passivel de adequações perante as percepções do professor dos anseios de seu público - os alunos.

Uma ação suscitada pelo entendimento do que envolve o ato de ensinar é querer elaborar o seu próprio material didático. Pela magnitude dos resultados alcançados ao aplicarem as atividades elaboradas em suas salas de aulas, os professores refletiram sobre como seria a Educação se os docentes, de um modo geral, tivessem tempo disponível para planejar atividades orientadoras de ensino, demonstrando com isso o reconhecimento desta necessidade e a mobilização para a elaboração do próprio material didático - e, com isso, a criação de situações desencadeadoras de aprendizagem:

Depois da atividade eu fiquei pensando: gente, mas já pensou se eu tivesse a possibilidade [...] de produzir as coisas minhas, de eu trabalhar da minha forma? O que eu acho complicado é que a gente não tem tempo de fazer aquilo todo dia, toda aula daquela forma, porque se a gente tivesse tudo esquematizadinho, a Educação ia dar um salto de qualidade. (Discurso do professor Al)

[...] Nossa! As aulas iam ser um show! (Discurso da professora Ad)

[...] Eu sei que é preciso e eu vi que é importante, realmente é importante. A gente vê nos olhos dos alunos: quando você apresenta esta parte histórica, a gente vê que eles se interessam pela história e a aula fica mais atrativa; é uma metodologia de ensino, é um ótimo recurso para você ensinar o aluno e eles ficam espantados com o antes e o depois - por exemplo, a resolução da equação do $2^{\circ}$ grau, mostrando pela resolução geométrica é bonito, é interessante [...]. (Discurso do professor L)

Dessa forma, o discurso do professor $L$ apresenta a sua percepção da necessidade da incorporação do processo histórico daquele conceito porque fez sentido para o aluno o que estava sendo estudado, pois havia uma situação desencadeadora de aprendizagem que exigia do professor um pouco mais de seu tempo na elaboração.

Conforme mencionamos, o curso de formação possibilitou aos participantes o compartilhamento, conduzindo à reflexão crítica das ações; por exemplo, quando a professora $\mathrm{Ad}$ apresentou a sua $\mathrm{AOE}$, ela recebeu sugestões do grupo para que sua atividade "chamasse a atenção dos alunos", 
conforme afirmaram os professores. O seguinte diálogo entre os professores Al e Ad evidencia a apresentação de sugestões dos companheiros do grupo:

Interessantes as duas atividades; agora na segunda atividade ficou muito bom também, mas eu penso que, por exemplo, se tivesse condições de introduzir na atividade, eu acho que isso mais no sentido de chamar a atenção do aluno, por exemplo, se fosse para um egípcio medir a área de um retângulo desses, como ficaria a anotação dele, como ele escreveria? Então eu acho que isso chamaria a atenção do aluno... (Discurso do professor Al)

Aguça mais, ao invés do simbólico, utilizar a retórica, né? (Discurso da professora Ad)

Exatamente. Eu percebi que você teve a preocupação de incluir aqui o aspecto histórico, mas eu acho que se você tivesse atentado para este detalhe aí você conseguiria demonstrar para o seu aluno que a forma que nós utilizamos hoje é uma evolução daquilo que era feito antigamente. Então eu acho que ficaria mais chamativo, mais comum com essa forma aqui. (Discurso do professor Al)

Quando o professor Al menciona que a atividade ficaria mais chamativa, refere-se ao que a professora Ad deveria dar à atividade para que pudesse desencadear aprendizagem significativa, o que é acatado por ela:

$\mathrm{Al}$, é uma sugestão muito boa mesmo. Vou estar aprofundando mais isso aí na linguagem retórica. É bem interessante a sua sugestão. (Discurso da professora $\mathrm{Ad}$ )

Porque assim como um egípcio mediria essa área? (Discurso do professor Al)

A corda de nós, né? (Discurso da professora Ad)

Não. É qual o procedimento de anotar essa medida. Porque esses medidores de terra eram funcionários do governo naquela época, então eles tinham que registrar isso em alguma coisa, então como ficaria esse registro? Então eu acho que o aluno... você conseguiria chamar a atenção dele. (Discurso do professor $\mathrm{Al})$

A linguagem mesmo. Valeu, eu vou pesquisar isso aí e aprofundar. Que interessante, vou anotar a sugestão. (Discurso da professora Ad)

A atividade da professora Ad reflete as incorporações sugeridas pelo grupo, assim como o aspecto evolutivo do conhecimento abordado; readequou a sua tarefa cujas características iniciais apresentavam uma preocupação excessiva com a manipulação algébrica. 
A incorporação da proposta lógico-histórica pelo professor $L$ foi revelada ao confrontarmos seu discurso quando começou o curso com seu discurso no último encontro:

[...] Você quer chegar nas raízes: como o cara pensou para fazer aquilo, como ele idealizou aquilo. Assim, na minha opinião, você pode me achar defasado e tal, parecendo um pensamento antigo, mas eu não aprendi assim na escola, atualmente o pessoal quer fazer isto, mas eu não sinto falta de saber, a hora que você vai fazer uma prova de vestibular não precisa nada disto [...]. Hoje o mundo nosso de prova, de concurso, de vestibular, não tem nada disso... O que eu acho assim... Ninguém consegue mudar minha cabeça, assim... Eu estudei na UEG, as disciplinas que falam tudo isso, eu quase não lia aqueles livros, até na própria disciplina da $\mathrm{Pq}$ eu tive muita dificuldade porque precisava ler muito livro falando disso e eu acho que a teoria nunca deu aula para saber como é, sei lá [...] eu tenho a sensação que a teoria nunca deu aula e põe as coisas muito fáceis... (Discurso do professor L no início do curso)

Você mostrou outro caminho para a gente, um caminho muito bom, um caminho competente de ensinar, um caminho atrativo e competente e que dá certo. (Discurso do professor L no término do curso)

Os discursos do professor $L$ demonstram a mudança no seu modo de encarar a proposta de organização do ensino que leva em conta a inserção do lógico-histórico do conceito. Além de mudar sua opinião, apresentou indícios do reconhecimento valorativo da proposta; ele encontrou um novo sentido para ensinar.

\section{Considerações finais}

Relacionando o processo de aprendizagem dos professores, de sua apropriação e objetivações dos princípios da teoria histórico-cultural ao que Vigotski (2008) concebe sobre aprendizagem, temos o seguinte: na zona de desenvolvimento proximal, a participação do outro assegura a mediação, sendo esse processo importante na consolidação das relações sociais e na formação da personalidade do indivíduo. Acreditamos, outrossim, que o compartilhamento de ações e a interação entre a pesquisadora e o grupo situam-se nesse patamar. A troca de saberes proporcionada pelo compartilhamento de ações, quando os grupos apresentavam suas atividades e davam sugestões entre si, a intervenção da pesquisadora fornecendo sugestões aos grupos quando elaboravam atividades orientadoras de ensino, suas objetivações, e a própria mediação dos colegas de curso elevaram o 
sentido inicial do curso aos participantes. As ações desenvolvidas desencadearam também o desejo de conhecer uma proposta de ensino com vistas a apropriar-se de um modo de ação geral que pudesse ser aplicado ao ensino da Matemática, gerando novas ações nos participantes do curso. Com isso, a apropriação de novos conhecimentos, dos princípios da teoria histórico-cultural, ao longo do curso, e a constituição de ações de qualidade nova configuram o nível da zona de desenvolvimento potencial e o conhecimento se torna real, como confirma Lopes (2009):

O movimento de aprendizagem, pela apropriação de novos conhecimentos em desenvolvimento, constitui o nível de desenvolvimento potencial, e quando essa dinâmica se completa, pela constituição de novas ações, com novas qualidades, o ciclo completa-se e o conhecimento alcança um nível real ( $p$. 188).

Concluído o curso, notamos que o movimento referente ao lógicohistórico do conteúdo algébrico é capaz de provocar mudanças qualitativas no aprender e no ensinar. Esse modo de organização do ensino é mais significativo principalmente quando o compartilhamento de ações, a colaboração e o coletivo se fazem presentes, pautados pela teoria históricocultural.

\section{Referências}

Araújo, E. S., \& Moura, M. (2008). Contribuições da teoria histórico-cultural à pesquisa qualitativa sobre formação docente. In M. Franco \& S. Pimenta (Orgs.), Pesquisa em educação. Possibilidades investigativas/formativas da pesquisaação (vol. 1, pp. 75-101). São Paulo: Loyola.

Cedro, W. L. (2008). O motivo e a atividade de aprendizagem do professor de Matemática: Uma perspectiva histórico-cultural (Tese de Doutorado). Faculdade de Educação, Universidade de São Paulo, São Paulo.

Cedro, W. L., \& Moura, M. (2010). Experimento didáctico: Un camino metodológico para la investigación en la Educación Matemática. Unión: Revista Iberoamericana de Educación Matemática, 22, 53-63.

Duarte, N. (2008). Sociedade do conhecimento ou sociedade das ilusões?. CampinasSP: Autores Associados.

Lemes, N. (2012). Evidências da produção de sentidos dos princípios da proposta didática lógico-histórica da álgebra por professores de Matemática em atividade de ensino (Dissertação de Mestrado). Universidade Federal de Goiás, Goiânia. 
Lopes, A. (2009). Aprendizagem da docência em Matemática: O Clube de Matemática como espaço de formação inicial de professores. Passo Fundo: Ed. UPF.

Moretti, V. (2007). Professores de Matemática em atividade de ensino: Uma perspectiva histórico-cultural para a formação docente (Tese de Doutorado) Faculdade de Educação, Universidade de São Paulo, São Paulo.

Moura, M. (1996). A atividade de ensino como unidade formadora. Bolema, 12, 29-43.

Moura, M. (2000). O educador matemático na coletividade da formação: Uma experiência com a escola pública (Tese de Livre Docência). Faculdade Educação, Universidade de São Paulo, São Paulo.

Moura, M. (Org.). (2010). A atividade pedagógica na teoria histórico-cultural. Brasília: Liber Livro.

Moyses, L. (2006). Aplicações de Vygotsky à Educação Matemática ( $7^{\mathrm{a}}$ ed.) Campinas, SP: Papirus.

Nóvoa, A. (1992). A formação da profissão docente. In A. Nóvoa (Org.), Os professores e a sua formação (pp. 14-33). Lisboa: Dom Quixote.

Rigon, A., Asbahr, F., \& Moretti, V. (2010). Sobre o processo de humanização. In M. Moura (Org.), A atividade pedagógica na teoria histórico-cultural (pp. 13-44). Brasília: Liber Livro.

Rosa, J., Moraes, S., \& Cedro, W. (2010). As particularidades do pensamento empírico e do pensamento teórico na organização do ensino. In M. Moura (Org.), $A$ atividade pedagógica na teoria histórico-cultural (pp. 67-80). Brasília: Liber Livro.

Sousa, M. (2004). O ensino da álgebra numa perspectiva lógico-histórica: Um estudo das elaborações correlatas de professores do Ensino Fundamental (Tese de Doutorado). Universidade Estadual de Campinas, São Paulo.

Vigotski, L. (2008). Pensamento e linguagem (4 $4^{\mathrm{a}}$ ed.). São Paulo: Martins Fontes. 


\section{MATHEMATICS TEACHERS IN TEACHING ALGEBRA ACTIVITIES: APPROPRIATIONS OF THE HISTORICAL-CULTURAL THEORY}

\section{Abstract}

This article aims to present the evidence of the appropriations of a group of mathematics teachers who, discontent with the situation of teaching algebra, participated in a training course. In this course, teachers had contact with the cultural-historical theory and guiding activities. This is a qualitative study which used a teaching experiment carried out with a group of mathematics teachers in Basic Education. The main results of this research indicate the importance of training activities that enable teachers to put up a movement of meaning production to learn and teach algebra in a proposal that understands mathematical knowledge as a historical and cultural product.

Keywords

Teacher education; Teaching algebra; Historical-cultural theory

PROFESORES DE LAS MATEMÁTICAS EN ACTIVIDAD DE ENSEÑANZA DEL ÁLGEBRA: APROPIACIONES DE LA TEORÍA HISTÓRICO-CULTURAL

\section{Resumen}

Este artículo tiene como objetivo presentar la evidencia de las apropiaciones de un grupo de profesores de matemáticas que, molestos con la situación de la enseñanza del álgebra, participaron en un curso de formación. En este curso, los profesores tuvieron contacto con la teoría histórico-cultural y actividades orientadoras. Se trata de un estudio cualitativo que utilizó un experimento didáctico llevado a cabo con un grupo de profesores de 
matemáticas de Educación Básica. Los principales resultados de esta investigación indican la importancia de las actividades de capacitación que permitan a los profesores se insertaren en un movimiento de producción de significado para el aprender y enseñar álgebra en una propuesta que entiende el conocimiento matemático como un producto histórico y cultural.

\section{Palabras-clave}

Formación del profesorado; Enseñanza del algebra; Teoría histórico-cultural

Recebido em novembro/2014

Aceite para publicação em agosto/2015

i Curso de Licenciatura em Matemática, Universidade Estadual de Goiás, Brasil.

ii Instituto de Matemática e Estatística, Universidade Federal de Goiás, Brasil.

Toda a correspondência relativa a este artigo deve ser enviada para: Núbia Cristina dos Santos Lemes, Universidade Estadual de Goiás (UEG), Campus Iporá, Av. R2, Qd. 01, Jardim Novo Horizonte II, 76200-000 Iporá, Goiânia, Brasil. E-mail: ncslemes@yahoo.com.br 
154 Núbia dos Santos Lemes \& Wellington Lima Cedro

ANEXO - Descrição das etapas do desenvolvimento do curso de formação e atividades realizadas

\begin{tabular}{|c|c|c|}
\hline \multicolumn{2}{|r|}{ ETAPAS } & ATIVIDADES \\
\hline $1^{a}$ & $\begin{array}{l}\text { Elaboração de exercícios } \\
\text { envolvendo conteúdos } \\
\text { sobre álgebra pelos } \\
\text { cursistas }\end{array}$ & $\begin{array}{l}\text { O objetivo desta etapa foi de conhecermos como os professores } \\
\text { organizavam seu ensino de álgebra. }\end{array}$ \\
\hline $2^{a}$ & $\begin{array}{l}\text { Compartilhamento dos } \\
\text { exercícios com o grupo }\end{array}$ & $\begin{array}{l}\text { Os professores apresentaram seus exercícios e, a partir da exposição, } \\
\text { discutimos o ensino de álgebra fazendo reflexões sobre o que } \\
\text { apresentaram, observando que refletem concepções expostas no artigo de } \\
\text { Fiorentini, Miorim, e Miguel (1993)'. Partindo da premissa de que iniciar uma } \\
\text { história do desenvolvimento da álgebra seria impossivel sem ter a } \\
\text { compreensão de como o homem aprendeu a contar e, por consequência, } \\
\text { como foi o surgimento dos números, propusemos o estudo dirigido do texto } \\
\text { de Cedro (2004). }\end{array}$ \\
\hline $3^{a}$ & $\begin{array}{l}\text { Estudo dos fundamentos } \\
\text { teóricos da perspectiva } \\
\text { lógico-histórica e do ensino } \\
\text { da álgebra }\end{array}$ & $\begin{array}{l}\text { Retomada a etapa anterior sob direcionamento das questões respondidas } \\
\text { pelos cursistas, esta etapa serviu para a resolução de atividades } \\
\text { orientadoras de ensino de álgebra nos pressupostos da teoria histórico- } \\
\text { cultural que contempem as etapas de evolução da linguagem algébrica, } \\
\text { levando os participantes a compreender como se deu o seu } \\
\text { desenvolvimento desde quando não existiam símbolos para a } \\
\text { representação do desconhecido. Esta etapa mesclou o estudo e discussão } \\
\text { dos textos de Moura }(1996)^{3} \text { e de Moretti (2007) }{ }^{4} \text { com o desenvolvimento } \\
\text { das atividades elaboradas por Lanner de Moura e Sousa (2004) })^{5} \text {, que } \\
\text { serviram como referência principal para a elaboraçăo e organização das } \\
\text { atividades do curso. }\end{array}$ \\
\hline $4^{a}$ & $\begin{array}{l}\text { Reelaboração das } \\
\text { propostas iniciais numa } \\
\text { perspectiva lógico-histórica }\end{array}$ & $\begin{array}{l}\text { Foi solicitado aos professores que reelaborassem seus exercícios tomando } \\
\text { como partida as tarefas que haviam exposto no início do curso e então } \\
\text { apresentassem essa atividade na etapa seguinte. Nesta etapa houve o } \\
\text { acompanhamento de cada professor na elaboração de sua proposta, } \\
\text { apontando-Ihes sugestões. Nas suas reelaborações, os professores } \\
\text { repensaram e levaram em consideração o percurso histórico da álgebra e } \\
\text { seus nexos conceituais. O coletivo sugeriu adaptações, apontou } \\
\text { possibilidades, ocasionando um novo olhar gerado pelas contribuições do } \\
\text { outro. }\end{array}$ \\
\hline $5^{a}$ & $\begin{array}{l}\text { Desenvolvimento nas salas } \\
\text { de aula das propostas } \\
\text { reelaboradas e escrita e } \\
\text { apresentação dos relatos } \\
\text { sobre o desenvolvimento } \\
\text { em suas salas de aula }\end{array}$ & $\begin{array}{l}\text { Todos os participantes desenvolveram em suas salas de aula a proposta } \\
\text { elaborada. Esta foi uma oportunidade na qual percebemos seus modos de } \\
\text { atuar à luz dos pressupostos da teoria histórico-cultural. Esta etapa se } \\
\text { prestou à reflexão, por cada participante, sobre o que foi incorporado da } \\
\text { teoria histórico-cultural em suas propostas e as representações desta em } \\
\text { suas salas de aula. Esta etapa permitiu compreendermos a influência do } \\
\text { curso na elaboração de atividades de ensino. }\end{array}$ \\
\hline
\end{tabular}

${ }^{1}$ Fiorentini, D., Miorim, M. A., \& Miguel, A. (1993). Contribuição para um repensar... A Educação algébrica elementar Pro-posições, $4(1-10), 78-91$

${ }^{2}$ Cedro, W. L. (2004). O espaço de aprendizagem e a atividade de ensino: O Clube de Matemática (Dissertação de Mestrado). Faculdade de Educação, Universidade de São Paulo. São Paulo.

${ }^{3}$ Moura. M. (1996). A atividade de ensino como unidade formadora. Bolema, 12, 29-43.

${ }^{4}$ Moretti, V. (2007). Professores de Matemática em atividade de ensino: Uma perspectiva histórico-cultural para a formaçăo docente (Tese de Doutorado). Faculdade de Educação, Universidade de São Paulo, São Paulo

${ }^{5}$ Lanner de Moura, A.., \& Sousa, M. (2004, julho). O lógico histórico da álgebra nas séries iniciais. Anais do VIII Encontro Nacional de Educação Matemática. Recuperado em 11 de janeiro de 2011 de hactonal de Educaça Mw. Matematica. Recuperado 